\title{
Mulemba
}

\section{Condenados da terra, sede agentes da Renascença Africana}

Paulo C. J. Faria

\section{(2) OpenEdition}

Journals

\section{Edição electrónica}

URL: http://journals.openedition.org/mulemba/436

DOI: 10.4000/mulemba.436

ISSN: 2520-0305

\section{Editora}

Edições Pedago

\section{Edição impressa}

Data de publição: 1 maio 2015

Paginação: 501-507

ISSN: 2182-6471

\section{Refêrencia eletrónica}

Paulo C. J. Faria, «Condenados da terra, sede agentes da Renascença Africana», Mulemba [Online], 5

(9) | 2015, posto online no dia 22 novembro 2016, consultado o 27 janeiro 2021. URL: http:// journals.openedition.org/mulemba/436 ; DOI: https://doi.org/10.4000/mulemba.436

Este documento foi criado de forma automática no dia 27 janeiro 2021.

Tous droits réservés 


\title{
Condenados da terra, sede agentes da Renascença Africana
}

\author{
Paulo C. J. Faria
}

\section{NOTA DO AUTOR}

Texto da apresentação pública da obra traduzida em língua portuguesa, dirigida por Malegapuru William MAKGOBA (Org.), Renascença Africana: A nova luta (Tradução de Narrativa Traçada; revisão do texto por Susana Ramos. Luanda, Edições Mulemba; Ramada, Edições Pedago, 2015, 500p. [«Reler África»]; título original: African Renaissance: The new struggle, 1999, Cape Town, Tafelberg Publishers), lido durante o «Ciclo de actividades em alusão ao Dia de África», no Anfiteatro principal da Faculdade de Ciências Sociais (FCS) da Universidade Agostinho Neto (UAN), em Luanda, em 15 de Maio de 2015.

«[...] Nesta ocasião, escolhi falar-vos da Regeneração da África. Sou africano e o meu orgulho na minha raça contrasta com uma opinião pública hostil. 0 africano está ciente da sua posição anómala e anseia por uma mudança. Dias melhores despontam em África. Parece que já consigo ver as suas correntes a romper, as suas planícies desertas a mergulhar na vermelhidão

das colheitas... É meu desejo que o termo regeneração seja entendido como a entrada numa nova vida, abraçando as várias etapas de uma existência superior e complexa.»

(Pixley Isaka Sema, membro fundador do Congresso Nacional Africano, em 1912)

A obra Renascença africana: A nova luta, organizada por Malegapuru William Makgoba, é o resultado de dois dias de uma histórica conferência que ocorreu nos dias 28 e 29 de 
Setembro de 1998 no Karos Indaba Hotel, Johannesburg, na República da África do Sul, contando com a participação de 470 pessoas, entre académicos, intelectuais, gestores e administradores.

2 A ideia central para a organização deste evento deve-se a Thabo Mbeki, então VicePresidente da África do Sul, considerado muito justamente o seu grande impulsionador e isso porque, dois anos antes, a 8 de Maio de 1996, tinha confessado: «Eu sou um africano!» (MAKGOBA et al. 2015: 16). Assim, é da simplicidade dessa auto-confissão que se segue a árdua tarefa de se procurar desvendar o sentido no nome predicativo do sujeito. O que é certo é que desse memorável encontro resultaram mais de 30 comunicações ricas e diversas. ${ }^{1}$

3 Por outro lado, a confissão de Mbeki engendra desafios, oportunidades e obrigações: será que compreendo quem sou, de onde venho e para onde vou neste mundo crescentemente globalizado onde diferenciações de toda a espécie estão sob pressão para se esbatarem, se ajustarem e se homogeneizarem? Em que sentido a minha vida, a minha educação, a minha forma de pensar e de interpretar o mundo são consistentes e compatíveis com essa identidade nitidamente africana? (MAKGOBA et al. 2015: 18). Afloram ainda questões acutilantes como - «corrupção, a instabilidade política constante, a justiça e desenvolvimento económico, a transformação económica, a trajectória económica e a fraca liderança política que têm vindo a caracterizar a África no período póslibertação» (MAKGOBA et al. 2015: 18-19). A certeza de que África, à semelhança de outros continentes, desempenha um papel essencial na tapeçaria da cultura mundial (MAKGOBA et al. 2015: 23), leva-nos, enquanto leitores, a partilhar algumas linhascentrais desta obra a medida que foram salpicando durante a leitura.

É deveras sugestivo a percepção de que «o novo mundo africano que a renascença africana pretende construir assenta na democracia, paz e estabilidade, no desenvolvimento sutentável e numa vida melhor para o povo, no não-racismo e não-sexismo, na igualdade entre as nações e num sistema justo e democrático de governação internacional» (MBEKI 2015: 30). Como satisfazer tais desígnios? Certamente, a resposta competeria ao leitor desvendá-la. Entretanto, tentamos identificar os seguintes eixos temáticos.

\section{Renascença Africana}

5 No que tange à «renascença africana», diz-nos Dialo Diop, que ela «apresenta como requisito prévio um certo saber histórico, o qual também se revela indispensável para se proceder a um prognóstico do possível contributo de África para o advento de uma humanidade genuína no futuro» (DIOP 2015: 37). Este saber, diz o Professor Philip V. Tobias, consiste no facto de que «nos últimos dois milhões de anos, África tem sido um extraordinário cadinho na história do planeta Terra (praticamente tudo o que há de importante ou frutífero começou em África)». O Professor Cheikh Anta Diop fundamenta a «natureza tipicamente africana da cultura egípcia antiga - a primeira forma de escrita (hieróglifos), os primeiros obeliscos e pirâmides, a primeira domesticação de animais e plantas, os primeiros cientistas nos domínios da matemática, astronomia, medicina, arquitectura, os primeiros navegadores em altomar, os primeiros filósofos, a primeira religião monoteísta com o deus Rá e o primeiro Estado-nação territorial com a unificação do Alto e Baixo Egípto sob o reinado de Amenófis IV - Aquenáton (1354-1327 a.C.)». 
6 A questão é o "porquê e como do declínio de África, cuja condição de fraqueza e vulnerabilidade se tornou de tal ordem que a expansão europeia conseguiu impôr o comércio de escravos e, posteriormente, a ocupação colonial nos primórdios dos tempos modernos? A perda de autonomia e soberania poderám justificar tamanho retrocesso histórico, decorrente, por um lado, de razias e das habituais conquistas militares e, por outro, da celebração de tratados desiguais e acordos injustos» (DIOP 2015: 38-39). Quanto a «marginalização actual de África», arguementa o pensador senegalês, «apresenta-se como o resultado previsível ou até expectável, da sua integração forçada e estruturalmente dependente num mercado global regido pela lei da troca desigual, desde a fase inicial da acumulação primitiva do capital até à fase da globalização financeira» (DIOP 2015: 39). O «muro da dependência e autoritarismo, de incompetência e corrupção, contra as aspirações dos povos africanos em termos de soberania, democracia política e bem-estar económico e social - conclui Diop - gera a necessidade de uma segunda libertação de África» (DIOP 2015: 39).

7 Efectivamente, houve tentativas feitas pela primeira geração de líderes africanos, designamente «o Plano de Acção de Lagos de 1980, todavia, foi substituído pelos programas de ajustamento estrutural inspirados por Washington logo em 1981, ou o Tratado de Abuja de 1981, o qual ditou a criação de uma Comunidade Económica Africana» (DIOP 2015: 39). Thazi Mazwai, no seu contributo sobre O físico da Renascença Africana alude a tal contexto como se tratasse de um acto de «engolir a pílula receitada no ocidente que matam o doente» (MAZWAI 2015: 476).

8 Entretanto, a questão que se coloca é saber - Onde radica a libertação? «A prioridade reside na descolonização dos espíritos, uma vez que qualquer processo de renascimento começa primeiramente com um certo despertar cultural». Ainda, «desenvolver um novo tipo de investigação cujos princípios traduzir-se-iam na emancipação humana em detrimento da alienação, na utilidade social em detrimento do lucro individual, chauvinismo ou egoísmo. Estabilidade é um requisito prévio para o desenvolvimento e que a integração política antecede a integração económica» (DIOP 2015: 40-42).

9 Atormentados pelas grandes questões sobre «taxa altíssima de desemprego e probreza crescente, sobre endividamento, subprodução agrícola e industrial, preservação do ecossistema» a solução política encontrar-se-ia numa "governação democrática e ética, capaz de ir ao encontro das necessidades e aspirações da maioria dos africanos. Neste quadro um Estado federal africano desempenharia uma função crucial, uma vez que os governantes são avaliados com base nos seus resultados, ao invés das suas intenções» (DIOP 2015: 42-43).

10 Alerta-nos Bernard Makhosezwe Magubane, que «quando contemplamos o caos em que África está mergulhada actualmente, importa não descurar a triste herança da escravatura, do colonialismo e do imperialismo, holocausto da escravização de África» (MAGUBANE 2015: 65). Na abordagem de Mahmood Mamdani «a renascença africana só é possível com uma intelligentsia focada em África», argumenta que intelligentsia na acepção lata russa, que «abarca todos os indivíduos que fomentam o pensamento criativo e lançam as bases do debate, seja nas artes e na cultura, seja no pensamento filosófico ou social» (MAMDANI 2015: 174).

11 Como o «resto de África está manchado por uma única pincelada, a do atraso. Urge descolonizar a intelligentsia, através do processo de desracialização individual, institucional e processual» (MAMDANI 2015: 176). Defendendo a «excelência através da autonomia»; liberdade intelectual que «proporciona as condições necessárias para 
debates intelectuais frutuosos, os quais se têm revelado fulcrais para o avanço das fronteiras do saber no continente» (MAMDANI 2015: 177). Micere Githae Mugo apela para premência de uma «cultura africana na educação para o desenvolvimentosustentado». Lembrando, de passagem a evocação de Ahmed Sekou Touré de que a cultura é fonte e produto de criação, na qual se aflora a «educação caracterizada pelam colocação de problemas e a resolução de problemas» contra «educação bancária» (MUGO 2015: 269-270).

\section{Agentes da Renascença Africana}

12 Aspiração pela renascença africana deve «representar a promessa de que cada um de nós», aduz Thabo Mbeki, «desempenhará, até ao fim o seu papel de activista genuíno no combate pelo renascimento do nosso continente» (MBEKI 2015: 25). «Não é possível falar de uma renascença africana quando se permite que a corrupção se mantenha como uma característica endémica dos sectores privado e público no nosso continente; [...] Quando o cancro do enriquecimento pessoal por meios corruptos constitui uma das causas do subdesenvolvimento e dos conflictos violentos dos quais nos procuramos libertar» (MBEKI 2015: 28). Ao proclamar que «[...] 0 ontem é um país estrangeiro - o amanhã a nós pertence!», Presidente Mbeki lança o seguinte repto aos líderes africanos: «devemos tornar o abuso do poder político por quem exerce esse poder, com vista à obtenção de riqueza material, estranho para o nosso continente e sistemas de governo» (MBEKI 2015: 27).

13 Parafraseando Léopold Sédar Senghor, o repto da renascença africana requereria «matar o homem (mulher) venha dentro de nós». Matar para renascer nas sombras da morte inscreve-se como prognóstico mais condiscente à multitude dos desafios hodiernos do continente. Todavia, a par desta medida Senghoriana, Mazwai sustenta desenvolvimento de uma intelligentsia focada em África para defender a resnascence africana. A qual seria realizável a fortiori através do «recurso às línguas e culturas africanas como instrumento de comunicação e veículo de desenvolvimento; a exploração dos ricos sistemas de conhecimento nativos e revitalização da economia e um desenvolvimento socioeconómico centrado nas pessoas e relacionado com África» (MAZWAI 2015: 481).

\section{NOTAS}

1. A obra, dividida em seis partes, contém uma «Introdução» redigida por Malegapuru William Makgoba, Thaninga Shope e Thami Mazwai (pp. 13-24); contém também um «Prólogo» escrito por Thabo Mbeki (pp. 25-33) e um «Epílogo. 0 aspecto físico da Renascença Africana», redigido por Thazi Mazwai (pp. 471-482), e ainda uma lista dos prelectores ao evento (pp. 483-485), bem como uma lista dos «Patrocinadores» suficientemente explicativa (pp. 487-499). A «Primeira Parte Renascença Africana: O contexto», contém textos de Dialo Diop (1. África: Passado e futuro da humanidade, pp. 37-43), de Bernard Makhosezwe Magubane (2. A Renascença Africana segundo uma 
perspectiva histórica, pp. 45-72), de Kwesi Kwaa Prah (3. A Renascença Africana ou senhores da guerra, pp. 73-98), de Georges Nzongola-Ntalaja (4. A crise na Região dos Grandes Lagos, pp. 99-113); de Ibbo Mandaza (5. Reconciliação e justiça social na África Austral: A experiência do Zimbabwe, pp. 115-128); de Willie Breytenbach (6. A história e o destino das minorias nacionais na Renascença Africana: A apologia de melhores fronteiras, pp. 129-139), de John Stremlau (7. Renascença Africana e relações internacionais, pp. 141-168) e de Mahmood Mamdani (8. A Renascença Africana só é possível com uma Intelligentsia focada em África, pp. 169-178); a «Segunda Parte - Renovação moral e valores africanos», contém unicamente os textos de N. Barney Pityana (9. A renovação dos valores morais africanos, pp. 181-193) e de Lesiba Teffo (10. Renovação moral e experiência(s) africana(s), pp. 195-216); a «Terceira Parte - Cultura e Educação», contém os textos de Mbulelo Mzamane (11. Perspectivas eurocêntricas e afrocêntricas na história africana antiga, pp. 219-228), de Pitika P. Ntuli (12. 0 elo em falta entre a cultura e a educação: estaremos ainda a perseguir deuses que não nos pertencem?, pp. 229-245), de Herbert W. Vilakazi (13. O problema das universidades africanas, pp. 247-257), de Micere Githae Mugo (14. A cultura africana na educação para o desenvolvimento sustentado, pp. 259-282), de Catherine A. Odora Hoppers, Teboho Moja e Thobeka Mda (15. Para o nosso último momento de passividade: O caminho a seguir, pp. 283-290); a «Quarta Parte - Transformação política e económica», contém os textos de Sémou Pathé Guèye (16. A Renascença Africana enquanto desafio histórico, pp. 293-214), de Sibusiso Vil-Nkomo e Johan Myburgh (17. A economia política de uma Rensacença Africana: Compreender as condições e formas estruturais, pp. 315-328), de Reuel J. Khoza (18. As estruturas institucionais que devem sustentar a Renascença Africana, pp. 329-338), de Wendy Luhabe (19. Maximizar o retorno dos activos de África, pp. 339-347), e de Nthobi Moahloli (20. Afrikatourism, pp. 349-352); a "Quinta-Parte - Ciência e Tecnologia», contém os textos de Ivan Van Sertima (As ciências perdidas de Áfrrica: Breve análise, pp. 355-379), de Karima Bounemra, Bem Soltane e Lishan Adam (22. O papel das tecnologias de informação e comunicação na Ciência e Tecnologia em África, pp. 381-392), de Mashupye Ratale Kgaphola e Namane Magau (23. A Renascença através da Ciência e Tecnologia, pp. 393-399), e de Mongane Wally Serote (24. Ciência e Tecnologia: Rumo à prosperidade em África, pp. 401-405); e, finalmente, a «Sexta-Parte - Meios de comunicação social e telecomunicações», regista os textos de Atukwei Okai (25. Atravessar o rubicão do tempo e enganar a guilhotina do tempo, pp. 409-413), de Chinweizu (26. Para uma Comunicação Social da Renascença Africana, pp. 415-426), de Joel Netshitenzhe (27. A Comunicação Social na Renascença Africana, pp. 427-436), de Edward Boateng (28. o papel da informação na promoção do desenvolvimento económico na África Subsahariana, pp. 437-449), de Sizwe Nxasana (29. As telecomunicações em África, pp. 451-455), de Keyan Tomaselli e Arnold Shepperson (30. Estudo dos meios de Comunicação Social e Renascimento da prática: Redescobrir as experiências africanas, pp. 457-469).

\section{AUTOR}

\section{PAULO C. J. FARIA}

20paulodrfaria12@gmail.com

Professor Auxiliar do Departamento de Ciência Política (DCP) da FCS - UAN e Regente do Curso de Ciência Política.(FCS) da Universidade Agostinho Neto (UAN); docente de Sociologia e de Latim da Faculdade de Ciências Humanas da Universidade Católica de Angola (UCAN).

Politólogo, é Professor Auxiliar do Departamento de Ciência Política (DCP) da Faculdade de Ciências Sociais (FCS) da Universidade Agostinho Neto (UAN) e Regente do Curso de Ciência 
Política. É Doutor em Política e Governança (2012), e possui um Mestrado em Relações Internacionais (2006) pela Universidade de Kent, Reino Unido. É licenciado em Filosofia e Humanidades (2002) pela Universidade Católica, Portugal. Publicou The post-war Angola: Public sphere, political regime and democracy (Newcastle upon Tyne, Cambridge Scholars Publishing, 2013, 320p.); «Ciência política: E Pluribus Unum», Mulemba - Revista Angolana de Ciências Sociais (Luanda), vol. III, n. ${ }^{\circ}$, Novembro de 2013, pp. 375-380. 